\title{
USO DE ALECRIM (Rosmarinus officinalis L.) NO PROCESSO DE DEFUMAÇÃO DE PEIXES CONTINENTAIS
}

Joel Artur Rodrigues DIAS ${ }^{1}$, Adriana Sousa ABREU ${ }^{1}$, Daniele Sousa da SILVEIRA ${ }^{1}$, Arthur dos Santos da SILVA ${ }^{1}$; Higo Andrade ABE ${ }^{1}$; John Lennon da Silva GOMES ${ }^{1}$; Francisco Alex

Lima BARROS $^{1}$; Evaldo Martins SILVA ${ }^{1}$; Fernanda dos Santos CUNHA ${ }^{2}$ Rodrigo Yudi FUJIMOTO $^{3} \&$ Carlos Alberto Martins CORDEIRO ${ }^{1}$

${ }^{1}$ Universidade Federal do Pará - Campus Bragança, Alameda Leandro Ribeiro, s/n, CEP 68600000, Bairro Aldeia, Bragança, Pará, Brasil.

${ }^{2}$ Universidade Tiradentes- Avenida Murilo Dantas, 300, CEP 49032-490, Bairro Farolândia, Aracaju, Sergipe, Brasil.

${ }^{3}$ Empresa Brasileira de Pesquisa Agropecuária unidade Tabuleiros Costeiros, Avenida Beira Mar, CEP 49025-040, Bairro Jardins, Aracaju, Sergipe, Brasil.

E-mail: camcordeiro2006@gmail.com

Recebido em: 26/02/2018

Resumo - Objetivou-se determinar a viabilidade da defumação a quente na presença da adição de sal e alecrim em três espécies de peixe de água doce, além da aceitação de cada peixe a partir do rendimento do produto e da análise das características organolépticas, bromatológicas e microbiológicas. Para o rendimento em peso, os resultados obtidos para a tilápia, o tambaqui e o tambacu defumados com sal e alecrim apresentaram valores médios de 45,73, 39,70 e 50,33\%, e defumados só com a adição de sal, 41,19, 40,29 e 53,95\%, respectivamente. Houve diferença significativa no teste de aceitação ( $\mathrm{p}<0,05)$ nos atributos sabor e cor para os tratamentos com adição de sal mais alecrim e só com a adição de sal. Em relação aos peixes, não houve diferenças significativas para as características aparência, aroma, sabor, textura e aceitação global. Nas análises microbiológicas, todas as amostras analisadas para coliformes totais encontraram-se dentro do padrão da legislação nacional, no entanto a contagem de bactérias aeróbias mesófilas apresentaram concentrações entre $10^{2}$ e $10^{4} \mathrm{UFC}^{-1} \mathrm{~g}^{-1}$ para os peixes defumados pelos diferentes tratamentos (sal mais alecrim e só adição de sal). Nas análises bromatológicas houve diferença significativa $(\mathrm{p}<0,05)$ nos quesitos tratamentos e peixes referentes aos componentes umidades $(63,66 \pm 9,49 \%)$, cinzas $(2,91 \pm 0,56 \%)$, lipídeos $\left(1,64 \pm 0,50\right.$ g. $\left.100 \mathrm{~g}^{-1}\right)$ e proteínas $(23,91 \pm 1,15$ g. $\left.100 \mathrm{~g}^{-1}\right)$. A adição de alecrim interferiu positivamente na aceitação e na intenção de compra dos peixes continentais defumados utilizando sal mais alecrim, que apresentou melhor escore de rendimento para o híbrido tambacu.

Palavras-chave: piscicultura, processamento, alecrim, análises organolépticas.

\section{USE OF ROSEMARY (ROSMARINUS OFFICINALIS L.) IN THE SMOKING PROCESS OF FRESHWATER FISH}

Abstract - The objective of this study was to determine the viability of hot smoking in the presence of salt and rosemary in three species of freshwater fish, in addition to the acceptance of each fish from the yield of the product and analysis of their organoleptic, bromatological and microbiological characteristics. For the yield by weight, the results obtained for tilapia, tambaqui and tambacu smoked with salt and rosemary presented average values of 45.73, 39.70 and 50.33\%, and the ones smoked only with the addition of salt $41.19,40.29$ and $53.95 \%$, respectively. There was a significant difference in the acceptance test $(\mathrm{p}<0.05)$ for the attributes of taste and color in treatments with addition of salt plus rosemary and only with the addition of salt. Regarding fish, there were no significant differences for the characteristics appearance, aroma, taste, texture and overall acceptance. In the microbiological analyses, all the samples analyzed for total coliforms are within the national legislation, but the count of mesophilic aerobic bacteria had concentrations 
between $10^{2}$ and $10^{4} \mathrm{CFU} \cdot \mathrm{g}^{-1}$ for fish smoked by the different treatments (salt with rosemary, and addition of salt only). There were significant bromatological differences $(\mathrm{p}<0.05)$ in the treatments and fish regarding humidity $(63.66 \pm 9.49 \%)$, ashes $(2.91 \pm 0.56 \%)$, lipids $(1.64 \pm 0.50$ g. $\left.100 \mathrm{~g} \mathrm{~g}^{-1}\right)$ and proteins $\left(23.91 \pm 1.15 \mathrm{~g} .100 \mathrm{~g}^{-1}\right)$. The addition of rosemary positively interfered the acceptance and intention to buy the smoked fish using salt and rosemary, which presented better yield score for the tambacu hybrid.

Keywords: fish farming, processing, rosemary, organoleptic analysis. 


\section{INTRODUÇÃO}

A produção nacional de pescado teve um aumento de $13,0 \%$ ao ano, resultando numa produção total de 1.431.974,4t, na qual 38,0\% (544.490,0 t) é oriunda da atividade aquícola. Neste setor, o estado do Pará contribuiu com 10,4 mil t do abastecimento do mercado interno e externo, tendo destaque para a produção de espécies comerciais marinhas e de água doce (Costa, Rodrigues \& Ricci, 2015; Brabo, Pereira, Santana, Campelo \& Veras, 2016).

Entre as espécies de água doce produzidas na piscicultura nacional, a tilápia (Oreochromis niloticus Linnaeus, 1758) representa 39\%, seguida pelo tambaqui (Colossoma macropomum Cuvier, 1816), que se encontra em ascensão com $26 \%$ do total produzido, tendo um crescimento significativo de $66 \%$ em comparação às últimas décadas (Kubitza, Campos, Ono \& Istchuk et al., 2012), e potencialidade para o seu híbrido tambacu (Colossoma macropomum đ̊ e Piaracutus mesopotamicus Holmberg, 1887 ๆ), que se destaca pelos produtores por apresentar maior ganho de peso, comparado à maioria das espécies redondas de águas continentais da Amazônia (ObaYoshioka, Costa, Borges \& Tavares-Dias, 2017).

Com o aumento da produção de pescado, o setor de beneficiamento pesqueiro passou a investir em técnicas de refinamento e praticidade de preparo e técnicas de conservação, a fim de melhorar o aproveitamento do pescado, como também para estimular o consumo do produto final que, mundialmente, está avaliado em $17 \mathrm{~kg}$ per capita enquanto que, a aquisição nacional ainda é discreta de $11,17 \mathrm{~kg}$ per capita, se comparada ao seu potencial produtivo, limitado à comercialização do pescado inteiro eviscerado (Evangelista-Barreto, Damacena, Cardoso, Marques \& Silva, 2017). Nesse cenário, o método da defumação atende a essa demanda para a qualidade do produto final, uma vez que a fumaça tem ação antioxidante e bacteriostática, que garante mudanças organolépticas positivas ao pescado beneficiado (Chagas, Menezes-Neta \& Oliveira-Filho, 2016). Entretanto, o seu errôneo manejo pode proporcionar produtos tão suscetíveis à contaminação quanto o pescado in natura (Gonçalves \& Cezarini, 2008).

Para obter bons resultados na defumação dos peixes, faz-se necessária a aplicação da fumaça em combinação aos fatores físicos de salga, cocção e secagem, e aos químicos, na deposição de substâncias químicas bacteriostáticas da fumaça (fenóis, aldeídos e ácidos orgânicos), além do controle constante da temperatura em cada uma das etapas da defumação (Chagas, Menezes-Neta \& Oliveira-Filho, 2016), que agregue maior valor ao produto e ofereça viabilidade econômica a sua cadeia produtiva (Emerenciano, Souza \& Franco, 2007).

$\mathrm{O}$ uso de especiarias como o alecrim (Rosmarinus officinalis L) visa à ação como antioxidante natural, por conta de as suas propriedades aromáticas, fenóis antioxidantes, 
antimicrobiana e antitumoral (Madsen et al., 1996; FIB, 2010). São relatados efeitos positivos do uso de alecrim: como antioxidante durante o processo de conservação da carne mecanicamente separada (CMS) e de filés salgados de tilápia (Oreochromis niloticus) durante 120 dias, armazenados a $-18{ }^{\circ} \mathrm{C}$ (Afonso \& Sant'Ana, 2008; Larosa, Carvalho, Vidotti, Lima \& Alves, 2012); e na conservação do camarão branco (Litopenaeus vannamei) descascado e congelado durante 120 dias a $-18^{\circ} \mathrm{C}$, que apresentou estabilidade lipídica e características organolépticas com o uso dessa especiaria (Seabra et al., 2011).

Com isso, o objetivo do referido trabalho foi determinar a viabilidade da defumação a quente com o uso do alecrim em três diferentes peixes de água doce, a partir das análises de rendimento, características organolépticas, bromatológicas e microbiológicas.

\section{MATERIAIS E MÉTODOS}

\section{OBTENÇÃO DAS AMOSTRAS}

Foram utilizadas três espécies de peixe de água doce, provenientes da Estação de Piscicultura da Universidade Federal Rural da Amazônia (UFRA), com 12 exemplares cada: tilápia, tambaqui e tambacu.

\section{PROCEDIMENTOS EXPERIMENTAIS}

Após a despesca, os animais foram insensibilizados com choque térmico e submetidos à sangria. Os procedimentos realizados para o abate dos vertebrados seguiram conforme a Resolução n 714 do Conselho Federal de Medicina Veterinária (CFMV) e do Colégio Brasileiro de Experimentação Animal (COBEA). Assim, os espécimes foram acondicionados em caixas térmicas com gelo a temperatura de $0^{\circ} \mathrm{C}$ e transportados até a área de processamento no Laboratório de Tecnologia do Pescado da Universidade Federal do Pará (UFPA), Campus Bragança, Pará. Os peixes in natura foram devidamente pesados, obtendo-se peso médio de 619,50 \pm 93,03 g (tilápia), $1.007,83 \pm 143,92 \mathrm{~g}$ (tambaqui) e 1.035,83 $\pm 184,10 \mathrm{~g}$ (tambacu). Após a pesagem, os peixes passaram por uma pré-lavagem para retirada do muco da superfície da pele, foram eviscerados, descamados e higienizados com água clorada $(5 \mathrm{ppm})$ e posteriormente pesados para a obtenção do cálculo de rendimento.

Após esses procedimentos, realizou-se o teste para avaliação de off-flavor em três etapas, no qual foram utilizados dois exemplares de cada espécie, retirando-se $1 \mathrm{~cm}^{2}$ da musculatura posterior caudal. Na primeira etapa, realizou-se a avaliação do off-flavor por meio do olfato; na etapa seguinte, as amostras foram pré-cozidas em forno de micro-ondas. Após o pré-cozimento, foi 
avaliada a presença ou ausência de odores típicos de off-flavor; na terceira etapa, as amostras foram degustadas, mas não ingeridas, por provadores pré-treinados, utilizando uma escala de avaliação de zero (0) a quatro (4) (Kubitza, 2004).

DEFUMAÇÃO

Para a técnica de defumação foram utilizados dois tratamentos: o primeiro constituído do processo de salga seca com $2,5 \%$ de $\mathrm{NaCl}$ e o segundo com salga seca $(2,5 \%$ de $\mathrm{NaCl})$ mais $1 \%$ de alecrim (Rosmarinus officinalis) em pó, utilizando, de peixes inteiros separados, seis indivíduos de cada espécie (tilápia, tambaqui e tambacu), identificados individualmente, acondicionados em basquetas plásticas e mantidos sob refrigeração a $4^{\circ} \mathrm{C}$ por 12 horas, constituindo, dessa forma, um delineamento inteiramente casualizado com dois tratamentos e seis repetições, em que cada indivíduo representou uma repetição.

O processo de defumação ocorreu em um defumador tradicional, com geração de fumaça na própria câmara de defumação. O combustível para produzir a fumaça foi de madeira não resinosa, disponível na região. Os peixes foram separados em três lotes; cada lote correspondia ao agrupamento de uma espécie (12 peixes), tendo sido colocado um lote de cada vez no defumador. A temperatura inicial foi de $50^{\circ} \mathrm{C}$, subindo gradativamente até $80^{\circ} \mathrm{C}$, na qual foi mantida e monitorada constantemente por termômetro digital, com tempo total de defumação de 8 horas. Ao término do processo, houve a espera do resfriamento em temperatura ambiente. Logo após, os peixes foram novamente pesados, acondicionados e refrigerados em temperatura de $4^{\circ} \mathrm{C}$ por 12 horas, para cálculo de rendimento, separação dos filés e realização da análise sensorial, de acordo com Gonçalves (2011).

\section{ANÁLISES SENSORIAIS}

As amostras dos peixes tilápia, tambaqui e tambacu defumados $( \pm 5 \mathrm{~g})$ foram avaliadas por 50 provadores não treinados, de ambos os sexos, da UFPA, com média de idade de $30 \pm 2,43$ anos. As amostras foram embaladas em papel alumínio, aquecidas em forno convencional (a gás) e oferecidas aos provadores, que as receberam de maneira aleatória em pratos codificados.

Para o teste de aceitação do produto, utilizou-se a escala hedônica de 9 pontos com extremos 1 (“desgostei muitíssimo”) e 9 (“gostei muitíssimo”), com vistas a estimar os atributos aparência, aroma, cor, sabor, textura e aceitação global (Dutcosky, 2009). Ao mesmo tempo, foi verificada a frequência de consumo, utilizando uma escala de 9 pontos com extremos 1 ("só comeria isto se fosse forçado(a)") e 9 ("comeria isto sempre que tivesse oportunidade"). Para calcular a intenção de compra e a preferência-ordenação, foi utilizada a metodologia estabelecida por Minim (2006), na qual a escala de 5 pontos com extremos 1 representa "certamente não compraria" e 5 "certamente 
compraria", e o número 1 e 2 representam as amostras preferidas e a segunda mais apreciada, respectivamente.

\section{COMPOSIÇÃO CENTESIMAL}

Para a realização das análises da composição centesimal, tanto dos peixes in natura quanto após a defumação, os valores de umidade foram determinados gravimetricamente por perda de peso, em estufa a $105^{\circ} \mathrm{C}$, até o seu peso constante; o extrato etéreo, por extração contínua com éter etílico em aparelho de Soxhlet; as cinzas, por incineração do material em mufla à temperatura de $550^{\circ} \mathrm{C}$; o nitrogênio total, pelo método de Microkjeldhal. Para expressar o resultado em proteína foi utilizado o fator 6,25, e o pH aferido em potenciômetro digital (Procyon), com todas as análises físico-químicas realizadas em triplicata (IAL, 1985; AOAC, 1995). E para as análises de carboidratos e valor calórico, seguiu-se o modelo de Peixoto, Sousa \& Mota (2000).

\section{ANÁLISES MICROBIOLÓGICAS}

Todas as amostras foram avaliadas quanto aos parâmetros coliformes totais e termotolerantes, utilizando a técnica de tubos múltiplos seriados; e para a determinação da contagem total de bactérias, utilizou-se a técnica padrão de contagem em placas, em duplicata (Vanderzant \& Splittstoesser, 1992; Brasil, 2003).

\section{ANÁLISES ESTATÍSTICAS}

Após a obtenção dos dados, estes foram submetidos aos testes de premissas de homocedasticidade e normalidade (Levene e Lilliefors, respectivamente). Não havendo distribuição normal, os dados foram transformados em arc sen raiz quadrada de $\mathrm{X}$.

Para as análises de rendimento, bromatológicas, de peso do produto final (peixe defumado) e a análise sensorial foi realizada a ANOVA, seguida, quando necessário, pelo teste de Tukey a nível de significância 0,05, com o auxílio do programa estatístico BioEstat 5.0 (Ayres, Ayres, Ayres \& Santos, 2007).

\section{RESULTADOS E DISCUSSÃO}

Os resultados de rendimento seguiram para tambacu defumado com adição de sal com alecrim (33,89\%) e só com adição de sal (36,55\%) não diferindo entre si (p > 0,05), mas obtiveram diferença significativa $(\mathrm{p}<0,05)$ quanto aos defumados de tilápia e tambaqui, o que pode estar relacionado à fundamentação de espécies híbridas, que tem como objetivo aumentar o rendimento da musculatura animal a partir do cruzamento entre espécies de alta linhagem, além de proporcionar animais com maior rusticidade, precocidade e produtividade, quando comparados com as espécies parentais (Ribeiro, Almeida, Paula, Porto \& Santin, 2016; Botero, Fresneda, Montoya \& Angel, 
2004) - hipótese que se confirma na Tabela 1, que compara o rendimento do tambacu (híbrido) e do tambaqui (espécie parental). Assim, quando comparado à tilápia, apesar da espécie não ser parental, o híbrido atendeu às características de maior rendimento ao grupo dos animais continentais mais produzidos no território nacional (Brabo, Pereira, Santana, Campelo \& Veras, 2016).

Tabela 1. Valores médios ( \pm desvio padrão) dos parâmetros peso total, peso eviscerado, peso do filé, rendimento da relação entre o peso total e o peso médio do filé e rendimento do peso eviscerado e do peso do filé.

\begin{tabular}{ccccccc}
\hline & \multicolumn{2}{c}{ Tilápia } & \multicolumn{2}{c}{ Tambaqui } & \multicolumn{2}{c}{ Tambacu } \\
\cline { 1 - 7 } PT & DAS & DS & DSA & DS & DSA & DS \\
\cline { 2 - 6 }$(\mathbf{g})$ & $622,33 \pm$ & $616,67 \pm$ & $1021,00 \pm$ & $994,67 \pm$ & $979,00 \pm$ & $1092,67 \pm$ \\
PE & $524,33 \pm$ & $520,00 \pm$ & $853,67 \pm$ & $860,00 \pm$ & $859,33 \pm$ & $957,00 \pm$ \\
$(\mathbf{g})$ & 51,68 & 105,93 & 88,25 & 162,37 & 164,03 & 149,23 \\
PF & $166,33 \pm$ & $143,67 \pm$ & $242,67 \pm$ & $250,33 \pm$ & $326,00 \pm$ & $398,67 \pm$ \\
$(\mathbf{g})$ & 39,18 & 26,96 & 40,21 & 66,57 & 35,33 & 70,92 \\
R1 & $26,48 \pm$ & $23,52 \pm$ & $23,65 \pm$ & $24,90 \pm$ & $33,89 \pm$ & $36,55 \pm$ \\
$(\%)$ & $4,23^{\mathrm{b}}$ & $3,12^{\mathrm{b}}$ & $2,40^{\mathrm{b}}$ & $2,07^{\mathrm{b}}$ & $4,71^{\mathrm{a}}$ & $3,22^{\mathrm{a}}$ \\
R2 & $45,73 \pm$ & $41,19 \pm$ & $39,70 \pm$ & $40,29 \pm$ & $50,33 \pm 1$ & $53,95 \pm$ \\
$(\%)$ & $4,79^{\mathrm{b}}$ & $4,62^{\mathrm{b}}$ & $6,33^{\mathrm{b}}$ & $7,20^{\mathrm{b}}$ & $2,38^{\mathrm{a}}$ & $6,69^{\mathrm{a}}$ \\
\hline
\end{tabular}

DSA: defumado com sal e alecrim (2,5\% de $\mathrm{NaCl}$ e $1 \%$ de alecrim); DS: defumado com sal (2,5\% de $\mathrm{NaCl})$; PT: peso total; PE: peso eviscerado; PF: peso do filé; R1: rendimento da relação entre o peso total e o peso médio do filé; R2: rendimento do peso eviscerado e do peso do filé; médias seguidas da mesma letra (linha) não diferem entre si pelo teste de Tukey $(\mathrm{p}<0,05)$.

Santos et al. (2007), ao estudarem o efeito das formas de processamento, troncos e filés de tilápia do Nilo (Oreochromis niloticus Linnaeus, 1758) e os seus efeitos na defumação com o uso do alecrim, verificaram que a presença dessa especiaria apontou menores valores de rendimento 20,81 e 32,17\% para troncos e filés, respectivamente, quando comparados aos defumados sem alecrim 25,58\% (tronco) e 39,10\% (filés), assim como observado nos resultados de Souza (2003), utilizando a mesma espécie, e de Franco et al. (2010), com matrinxã (Brycon cephallus Gunther, 1869). Entretanto, esses autores observaram menores rendimentos quando comparados aos encontrados nas espécies deste estudo, o que pode estar relacionado ao fato de o rendimento dos produtos ser um parâmetro variável que depende de alguns fatores, como a técnica de defumação e a espécie (Godoy et al., 2010). 
Para as análises de aceitação quanto à aparência, ao aroma, à cor, ao sabor, à textura e à aceitação global das espécies submetidas aos tratamentos de defumação com adição de sal e alecrim e adição de sal $(2,5 \%$ de $\mathrm{NaCl})$, expressadas na Tabela 2, não houve diferença $(\mathrm{p}>0,05)$ aos atributos aparência, aroma, textura e aceitação global entre as espécies e os tratamentos avaliados. Todavia, os parâmetros sabor e cor de todas as espécies analisadas apresentaram maiores escores (p $<0,05)$ aos tratamentos submetidos ao processo de defumação com sal e alecrim $(2,5 \%$ de $\mathrm{NaCl}$ mais $1 \%$ de alecrim).

Tabela 2. Valores médios ( \pm desvio padrão) do teste de aceitação, da análise bromatológica e da microbiológica dos peixes defumados.

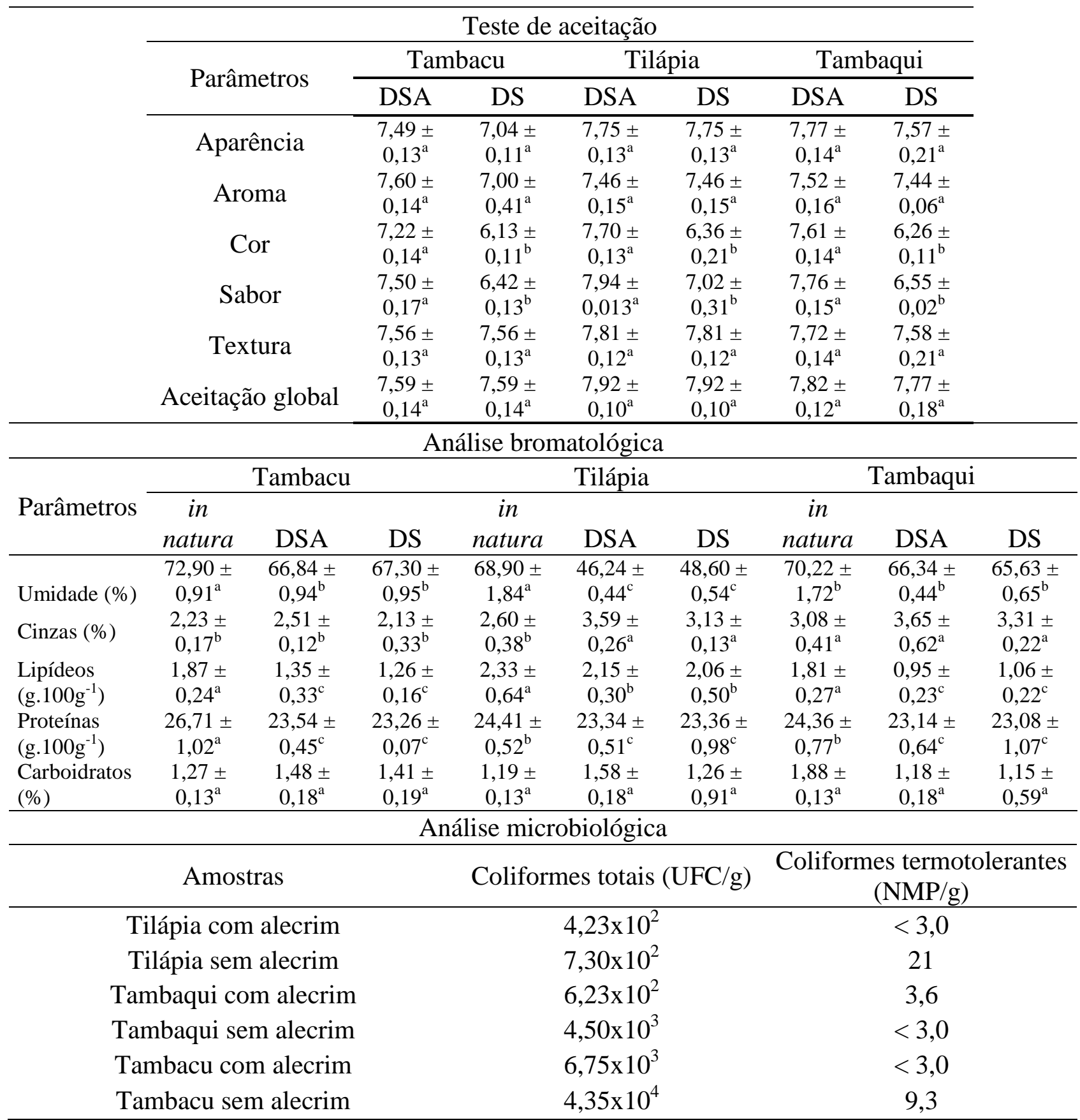


DSA: defumado com sal e alecrim (2,5\% de $\mathrm{NaCl}$ e $1 \%$ de alecrim); DS: defumado com sal (2,5\% de $\mathrm{NaCl})$; médias na mesma coluna com a mesma letra não diferem significativamente pelo teste de Tukey $(\mathrm{p}>0,05)$.

Os atributos cor e sabor ficaram mais evidentes nos produtos com adição de sal e alecrim. No presente trabalho, a adição de alecrim a $1 \%$ proporcionou maior aceitação do produto final, realçando as suas características organolépticas, assim como aos produtos observados por Seabra et al. (2011) - camarão branco (Litopenaeus vannamei) defumado com alecrim. Esses resultados podem ser atribuídos ao processamento da defumação, no qual temperaturas acima de $35^{\circ} \mathrm{C}$ desencadeiam a gordura muscular, proporcionando melhor aparência, brilho e retenção de substâncias aromáticas, pois as gotículas de gordura ajudam na detenção dos componentes aromáticos da fumaça, conferindo sabor, cor e odor agradáveis ao produto final (Fellows, 2006; Gonçalves, 2011; Galvão \& Oetter, 2014).

Em relação ao sabor, a tilápia, comparada aos outros peixes, apresentou melhor suavidade de sua carne quando agregado o alecrim ao processamento de defumação. De forma geral, os resultados obtidos por meio do teste de aceitação demonstraram que os peixes defumados apresentaram uma "boa aceitação" por parte dos avaliadores — 88, 86,88 e 84,33\% para tilápia, tambaqui e tambacu, respectivamente.

Em relação à frequência de consumo ou à escala de atitude, as maiores notas foram atribuídas aos pescados defumados, que estão na faixa maior que 5 ("comeria isso sempre que tivesse oportunidade"), evidenciando os peixes tilápia com sal e alecrim (88\%), tambaqui com sal e alecrim (80\%) e tambaqui só com sal (78\%). Quanto aos produtos com valor igual a 5, conferiram as notas mais expressivas para os peixes tambacu com sal e alecrim (24\%), tilápia com sal e alecrim (12\%), tambaqui (22\%) e tambacu (10\%) só com sal; e para os peixes com valores menores que 5, o tambacu com sal e alecrim recebeu a nota menos expressiva, na faixa 2 ("só comeria isto se não pudesse escolher outro alimento"), equivalendo a $8 \%$.

Segundo Dutcosky (2009) e Minim (2006), o objetivo da frequência de consumo é medir o grau de aceitação do produto com base em atitudes do consumidor em relação à periodicidade a qual estaria disponível para consumi-lo. Dos produtos analisados, a tilápia e o tambaqui, com e sem alecrim, foram classificados com notas acima de cinco, apontando boa aceitação de consumo (Dutcosky, 2009), resultados que refletem a aprovação das amostras pelos julgadores.

As análises obtidas da composição centesimal descritas na Tabela 2 apresentam perda significativa $(\mathrm{p}<0,05)$ na umidade do pescado in natura para o produto final (peixes defumados), resultado que aponta para uma possível perda significativa $(\mathrm{p}<0,05)$ de água livre intramuscular, após o processamento da defumação, em todas as espécies avaliadas, sobressaindo-se a tilápia (maior perda dos componentes úmidos), tanto para o tratamento com adição de alecrim (1\% de 
alecrim mais 2,5\% de $\mathrm{NaCl})$ quanto para o tratamento só com a adição de sal (2,5\% de $\mathrm{NaCl})$, em comparação ao tambaqui e ao tambacu. Essas análises contrapuseram-se às observadas por Fogaça et al. (2014), que notaram maior percentual de umidade nos tratamentos contendo maiores concentrações de alecrim em filés de tambaquis defumados, estando a especiaria relacionada ao seu efeito antioxidante em impedir danos celulares da matéria, prevenindo, dessa forma, a perda hídrica durante a defumação; assim como às observadas por Hang (2011), que trabalharam com filés de salmão (Salmo salar L.).

A fração de cinzas em peixes continentais varia entre 0,90 e 3,39\% (Contreras-Guzmán, 1994), parâmetro que colabora com os resultados encontrados no trabalho supracitado, com maiores concentrações de minerais para a tilápia e o tambaqui, que se diferiram $(\mathrm{p}<0,05)$ do tambacu, que por ter apresentado uma maior quantidade de rendimento na carne, a concentração de minerais intramusculares derivados dos espinhos, pode ter sido baixa, acarretando assim numa menor concentração de cinzas quando comparada com as outras espécies avaliadas (Gonçalves, 2011).

Os valores médios de lipídeos, carboidratos e proteínas dos peixes defumados diferiram $(\mathrm{p}<$ 0,05) em relação ao produto in natura. Todos os tratamentos analisados apresentaram teor lipídico menor que 3\%, classificados como pescado de baixo teor de gordura (Pigot e Tucker, 1990). Todavia, a variação da concentração lipídica entre as espécies pode estar relacionada a diferença no sexo, na idade, na dieta, entre outros fatores, o que colabora com os resultados obtidos por RamosFilho, Ramos, Hiane \& Souza (2008) e Viana, Silva, Fernandes \& Santos (2013), trabalhando com espécies dos gêneros Pseudoplatystoma, Piaractus e Salminus; e Lutjanus, Ocyurus, Opisthonema e Mugil, respectivamente. Para a concentração de carboidrato, os valores médios das amostras foram de $1,34 \pm 0,28 \%$, resultados que se assemelham aos propostos por Ogawa e Maia (1999) para peixes em geral. Com relação aos teores de proteínas, todas as espécies analisadas apresentaram percentual superior a $20 \%$, sobressaindo o valor médio $(\mathrm{p}<0,05)$ do híbrido tambacu para esse parâmetro, o que colabora com os resultados encontrados por Sant'Ana, Ducatti \& Ramires (2010), com filés defumados de cachara (Pseudoplatystoma fasciatum), e Ramos-Filho, Ramos, Hiane \& Souza (2008), com pacu (Piaractus mesopotamicus). Essas respostas nutricionais podem estar relacionadas ao fato de a defumação ocorrer à desidratação do produto que retém maior concentração de nutrientes (Galvão \& Oetter, 2014).

Já nas análises microbiológicas (Tabela 2), todas as amostras para coliformes totais encontram-se dentro do padrão, e de coliformes termotolerantes, abaixo do limite preconizado pela legislação (Brasil, 2003). Mesmo não havendo padrão nas legislações federal e estadual, fez-se a contagem de bactérias aeróbias mesófilas: entre $10^{2}$ e $10^{4}$ UFC.g- $_{-}{ }^{1}$ para os pescados defumados pelos diferentes tratamentos. Tal determinação foi realizada, uma vez que o elevado número dessas 
bactérias poderá acarretar no menor tempo de prateleira do produto.

Para os padrões da legislação vigente (Brasil, 2003), as análises de pescado defumado para peixes, moluscos e crustáceos, refrigerados ou congelados, devem apresentar ausência de Salmonela em $25 \mathrm{~g}$, coliformes termotolerantes $10^{2} \mathrm{NMP} . \mathrm{g}^{-1}$ e $S$. aureus máximo de $5 \times 10^{2}$ UFC.g $\mathrm{g}^{-1}$. Costa et al. (2008), ao trabalharem com defumação de filés de piau-vermelho (Leporinus copelandii Steindachner, 1875) com uso de fumaça líquida, encontraram um elevado número de bactérias aeróbias mesófilas, tanto para a matéria-prima quanto para os produtos analisados. Já para a análise de coliformes termotolerantes, os valores abaixo do limite preconizado pela legislação coincidiram com os obtidos neste trabalho (Sousa \& Conceição, 2007; Galvão \& Oetter, 2014).

Para os resultados das análises microbiológicas, as amostras dos pescados tratados com a adição de sal e alecrim apontaram para valores de contagem de coliformes totais e termotolerantes inferiores aos tratamentos sem adição de alecrim, comprovando a ação antimicrobiana da especiaria, conforme Sousa \& Conceição (2007).

\section{CONCLUSÕES}

A adição de alecrim alterou o rendimento das espécies, o que resultou em uma boa aceitação dos parâmetros sabor, cor, bromatológicos e microbiológicos dos peixes defumados, no qual a defumação a quente com a especiaria foi eficaz a aceitação dos peixes estudados, que sobressaiu no escore de rendimento o híbrido tambacu.

\section{REFERÊNCIAS}

AFONSO, M. S. \& SANT'ANA, L. S. (2008). Effects of pretreatment with rosemary (Rosmarinus officinalis L.) in the prevention of lipid oxidation in salted tilapia fillets. J. Food Qual., 31(5):586595. http://dx.doi.org/10.1111/j.1745-4557.2008.00222.x

ASSOCIATION OF OFFICIAL ANALYTICAL CHEMISTS (AOAC) (1995). Official Methods of Analysis of the Association of Official Analytical Chemists. 14. ed. Arligton: AOAC. 1141p.

AYRES, M., AYRES JR., M., AYRES, D. L. \& SANTOS, A. S. (2007). BioEstat 5.0: Aplicações Estatísticas nas Áreas das Ciências Biológicas e Médicas.

BOtero, M., FRESNEDA, A., MONTOYA, A. F. \& ANGEL, M. O. (2004). Descripción del desarrollo embrionario de zigotos híbridos obtenidos por el cruce de machos de Cachama Blanca (Piaractus brachypomus) y hembras de Cachama Negra (Colossoma macropomum). Rev. Col. Ciênc. Pec., 17:38-45.

BRABO, M. F., PEREIRA, L. F. S., SANTANA, J. V. M., CAMPElO, D. A. V. \& VERAS, G. C. (2016). Cenário atual da produção de pescado no mundo, no Brasil e no estado do Pará: ênfase na 
aquicultura. Acta Fisheries Aquat. Res., 4(2):50-58. http://dx.doi.org/10.2312/Actafish.2016.4.2.5058

BRASIL. MINISTÉRIO DA AGRICULTURA, PECUÁRIA E ABASTECIMENTO. (2003). Instrução normativa $\mathrm{n}^{\circ} 62$, de 26 de agosto de 2006. Oficializa os métodos analíticos oficiais para análises microbiológicas para controle de produtos de origem animal e água. Diário Oficial da União, Brasília, seção I, p. 14.

BRASIL. MINISTÉRIO DA PESCA E AQUICULTURA (2011). Boletim estatístico da Pesca e Aquicultura Brasil. Acessado em abril de 2016 em http://www.icmbio.gov.br/cepsul/images/stories/biblioteca/download/estatistica/est_2011_bol_bra. pdf

CHAGAS, A. M., MENEZES-NETA, I. S. \& OLIVEIRA-FILHO, P. R. C. (2016). Rendimento, umidade e aceitação sensorial do carapicu (Eucinostomus melanopterus Bleeker, 1863) submetidos a diferentes métodos de defumação. Acta Fisheries Aquat. Res., 4(2):110-116. http://dx.doi.org/10.2312/Actafish.2016.4.2.110-116

COLÉGIO BRASILEIRO DE EXPERIMENTAÇÃO ANIMAL (COBEA). (2012). Resolução nº 714 do Conselho Federal de Medicina Veterinária (CFMV). Acessado em junho de 2018 em portal.cfmv.gov.br/lei/download-arquivo/id/326

CONTRERAS-GUZMÁN, E. S. BIOQUíMICA DE PESCADOS E DERIVADOS. JABOTICABAL: FUNEP, 1994.

COSTA, A. L. S., RODRIGUES, M. S. \& RICCI, F. (2015). Caracterização da piscicultura na região de Ariquemes, no estado de Rondônia. Campo - Território: Rev. Geog. Agrária, 10(20):512537.

COSTA, A. P. R., ANDRADE, D. R., VIDAL-JÚNIOR, M. V., CORDEIRO, C. A. M., SOUZA, G., ERTHAL JUNIOR, M. \& SOUZA, C. L. M. (2008). Defumação de filé de piau-vermelho (Leporinus copelandii) com o uso de fumaça líquida. Rev. Ceres, 55(4):2251-2257.

DUTCOSKY, S. D. (2009). Análise Sensorial de Alimentos. Curitiba: Champagnat.

EMERENCIANO, M. G. C., SOUZA, M. L. R. \& FRANCO, N. P. (2007). Defumação de ostras Crassostrea gigas: a quente e com fumaça líquida. Ciênc. Anim. Bras., 8(2):235-240.

EVANGELISTA-BARRETO, N. S., DAMACENA, S. S., CARDOSO, L. G., MARQUES, V. F. \& SILVA, I. P. (2017). Condições higiênicas sanitárias e grau de frescor do pescado comercializado no mercado de peixes em achoeira, Bahia. Rev. Bras. Hig. Sanid. Anim., 11(1).

FELLOWS, P. J. (2006). Tecnologia do processamento de alimentos: princípios e prática. 2. ed. Porto Alegre: Artmed. p.323-343.

FOGAÇA, F. H. S., VIEIRA, S. G. A., ARAÚJO, T. D. S., SANTOS-FILHO, L. G. A., MAGALHÃES, J. A. \& COSTA, N. L. (2014). Oxidação lipídica em filés de tambaqui (Colossoma macropomum) defumados com alecrim (Rosmarinus officinalis). PUBVET, 8(10).

FOOD INGREDIENTS BRASIL (FIB). (2010). Agentes antimicrobianos químicos e naturais. Food Ingred. Bras., 15:36-42.

FRANCO, M. L. R. S., VIEGAS, E. M. M., KRONKA, S. N., VIDOTTI, R. M., ASSANO, M. \& 
GASPARINO, E. (2010). Efeitos do processo de defumação a quente e a frio sobre as propriedades organolépticas, o rendimento e a composição de filé de matrinxã. Rev. Bras. Zootec., 39(4):695700. http://dx.doi.org/10.1590/S1516-3598201000040000

GALVÃO, J. A. \& OETTER, M. (2014). Qualidade e processamento de pescado. Rio de Janeiro: Elsevier. p. 211-233.

GODOY, L. C., FRANCO, M. L. R. S., FRANCO, N. P., SILVA, A. F., ASSIS, M. F., SOUZA, N. E., MATSUSHITA, M. \& VISENTAINER, J. V. (2010). Análise sensorial de caldos e canjas elaborados com farinha de carcaças de peixe defumadas: aplicação na merenda escolar. Ciênc. Tecnol. Aliment., 30(Supl. 1):86-89. http://dx.doi.org/10.1590/S0101-20612010000500014

GONÇALVES, A. A. (2011). Tecnologia do pescado: ciência, tecnologia, inovação e legislação. São Paulo: Atheneu. p. 166-178.

GONÇALVES, A. A. \& CEZARINI, R. (2008). Agregando valor ao pescado de água doce: Defumação de filés jundiá (Rhamdia quelen). Rev. Bras. Eng. Pesca, 3(2):63-79. http://dx.doi.org/10.18817/repesca.v3i2.73

HANG, A. T. N. (2011). Effects of dietary oxidation status and vitamin E level on performance, fillet quality and robustness to acute stress in Atlantic salmon (Salmo salar L.) [Dissertação de Mestrado]. Noruega: Universidade Norueguesa de Ciências da Vida.

INSTITUTO ADOLF LUTZ (IAL) (1985). Normas analíticas do Instituto Adolfo Lutz. São Paulo: Instituto Adolfo Lutz.

LAROSA, G., CARVALHO, M. R. B., VIDOTTI, R. M., LIMA, T. M. A. \& ALVES, V. F. (2012). Elaboração de produto cárneo de tilápia com antioxidantes visando sua utilização como recheio ou acompanhamento da refeição. Alim. Nutr., 23(4):609-617.

KUBITZA, F. (2004). Coletânea de informações aplicadas ao cultivo do tambaqui, pacu e de outros peixes redondos. Rev. Panor. Aquicult., 60(14):27-39.

KUBITZA, F., CAMPOS, J. L., ONO, E. A. \& ISTCHUK, P. I. (2012). Panorama da piscicultura no Brasil: Estatística, espécies, pólos de produção e fatores limitantes à expansão da atividade. Panor. Aquicult., 22(132):14-25.

MADSEN, H. L., NIELSEN, B. R., BERTELSEN, G. \& SKIBSTED, L. H. (1996) Screnning of antioxidants between assays based on ESR spin trapping an electrochemical measurement of oxygen consumption. Food Chem., 57(2): 331-337. https://doi.org/10.1016/0308-8146(95)00248-0

MINIM, V. P. R. (2006). Análise sensorial: estudo com consumidores. 2. ed. Viçosa: Editora da UFV. 225p.

OBA-YOSHIOKA, E. T., COSTA, R., BORGES, M. \& TAVARES-DIAS, M. (2017). Blood variables of hybrid tambacu farmed in Amapá state, Northern Brazil. Vet. Zootec., 24(1):201-208.

OGAWA, M. \& MAIA, E. L. (1999). Manual de pesca: ciência e tecnologia do pescado. São Paulo: Varela.

PEIXOTO, M. R. S., SOUSA, C. L. \& MOTA, E. A. D. S. (2000). Utilização de pescada (Macrodon ancylodon) de baixo valor comercial para obtenção de surimi empanado na elaboração 
de salsicha com sabor de camarão. Bol. CEPPA, 18(2):151-162.

PIGOT, G. \& TUCKER, B. (1990). Sea food effects of technology on nutrition. Nova York: Marcel Dekker.

RAMOS-FILHO, M. M., RAMOS, M. I. L., HIANE, P. A. \& SOUZA, M. T. (2008). Perfil lipídico de quatro espécies de peixes da região pantaneira de Mato Grosso do Sul. Ciênc. Tecnol. Alim., 28:361-365.

RIBEIRO, L. S., AlMEIDA, S. S. N., PAUlA, F. G., PORTO, R. N. G. \& SANTIN, A. P. I. (2016). Descrição histológica de órgãos viscerais de tambacu (Piaractus mesopotamicus $\times$ Colossoma macropomum). Enciclop. Biosf., 13:411-421.

SANT'ANA, L. S., DUCATTI, C., \& RAMIRES, D. G. (2010). Seasonal variations in chemical composition and stabla isotopes of farmed and wild Brazilian freshwater fish. Food Chem., 122:7477. http://dx.doi.org/10.1016/j.foodchem.2010.02.016

SANTOS, L. D., ZARA, R. F., VISENTAINER, J. V., MATSUSHITA, M., SOUZA, N. E. \& FRANCO, M. L. R. S. (2007). Avaliação sensorial e rendimento de filés defumados de tilápia (Oreochromis niloticus Linnaeus, 1757) na presença de alecrim (Rosmarinus officinalis). Ciênc. Agrotecnol., 31(2):406-412. http://dx.doi.org/10.1590/S1413-70542007000200021

SEABRA, L. M. J., DAMASCENO, K. S. F. S. C., ANDRADE, S. A. C., DANTAS, M. M. G., SOARES, N. K. M. \& PEDROSA, L. F. C. (2011). Effect of rosemary on the quality characteristics of white shrimp (Litopenaeus vannamei). J. Food Qual., 34(1):363-369. https://doi.org/10.1111/j.1745-4557.2011.00402.x

SOUSA, T. M. P. \& CONCEIÇÃO, D. M. (2007). Atividade antibacteriana do alecrim (Rosmarinus officinalis L.). Ensaios Ciênc., 5(5):7-13.

SOUZA, M. L. R. (2003). Processamento do filé e da pele de tilápia do Nilo (Oreochromis niloticus): aspectos tecnológicos, composição centesimal, rendimento, vida útil do filé defumado e teste de resistência da pele curtida [Tese de Doutorado]. Jaboticabal: Universidade Estadual Paulista "Júlio de Mesquita Filho".

VANDERZANT C. E. \& SPLITTSTOESSER D. F. (1992). Compendium of methods for the microbiological examination of food. 3. ed. Washington, D.C.: American Public Health Association. 1219 p.

VIANA, Z. C. V., SILVA, E., FERNANDES, G. B. \& SANTOS, V. L. C. S. (2013). Composição centesimal em músculo de peixes no litoral de estado da Bahia/Brasil. Rev. Ciênc. Méd. Biol., 12(2):157-162. http://dx.doi.org/10.9771/cmbio.v12i2.6955 